\title{
Preservação da memória institucional relativa a projetos universitários através do sistema aberto de arquivamento de informação (SAAI)
}

La preservación de la memoria institucional de los proyectos universitarios a través del sistema de información de archivos abiertos (OAIS)

Preservation of the institutional memory of university projects using the open archival information system (OAIS)

Gilberto Fladimar Rodrigues VIANA (1),Telma Campanha de Carvalho MADIO (2), Daniel FLoRES (3)

(Universidade Estadual Paulista, Programa de Pós-Graduação Ciência da Informação, Av. Higyno Muzzi Filho, 737 , Cidade Universitária, Marília, SP, Brasil; (1) vrfgpc@gmail.com; (2) Universidade Federal de Santa Maria, Campus, CEP 97105900, Camobi, Santa Maria, RS, Brasil, telmaccavalho@marilia.unesp.br; (3) danielflores@ufsm.br.

\section{Resumen}

Se aborda la preservación de la memoria institucional de la Universidade Federal de Santa María (UFSM) de Brasil, que consta de los proyectos desarrollados en la institución y considerados patrimonio documental. Los datos de dichos proyectos se almacenan en la base de datos de la institución, denominada Sistema de Información para la Enseñanza (SIE), en funcionamiento desde 1992. Se analizan las implicaciones teóricas y prácticas de los conceptos de memoria institucional, base de datos y medios digitales, y de la aplicación del estándar NBR 15472 que especifica el modelo del sistema archivo abierto de información (SAAI), con énfasis en su sección 4.

Palabras clave: Archivos universitarios. Universidad Federal de Santa María (Brasil). Archivos digitales. OAIS. Memoria institucional. Brasil.

\section{Introdução}

Este trabalho tem como tema a preservação da memória institucional da Universidade Federal de Santa Maria - UFSM, localizada na cidade de Santa Maria, no estado do Rio Grande do Sul, através de seu banco de dados, criado em 1992, denominado Sistema de Informações para o Ensino - SIE. Tem-se como objetivo a análise da preservação desta produção institucional sob os auspícios da norma da Associação Brasileira de Normas Técnicas - ABNT, Norma Brasileira - NBR 15.472, do modelo de referência para um sistema aberto de arquivamento de informação - SAAI, considerando a realidade do registro das informações arquivísticas dos projetos que fazem parte do banco de dados denominado SIE. Enfatiza-se que o Conselho Nacional de Arquivo - CONARq, através da Câmara Técnica de Documentos Eletrônicos está analisando a alteração da denominação dos pacotes de informação tratados no SAAI.

\begin{abstract}
The preservation of the institutional memory of the Federal University of Santa Maria (UFSM), Brasil, consisting of those projects that have been considered as documentary heritage, is addressed. The details of these projects are stored in the database of the institution, called Information System for Education, in operation since 1992. Various theoretical and practical implications are analyzed, specially those of the concepts of institutional memory, database and digital media, and of the application of the NBR 15472 standard that specifies the open archives information system model (OAIS), with emphasis in its Section 4.
\end{abstract}

Keywords: Academic archives. Federal University of Santa María (Brazil). Brazil. Digital archives. OAIS. Institutional memory.

Procurou-se também averiguar como se constitui a dinâmica de relação entre o produtor, a administração e o consumidor. Enfatiza-se que este artigo é a continuação das reflexões do trabalho de doutorado.

O registro das informações é realizado através de metadados, que uma vez preenchidos, tramita eletronicamente para as várias instâncias para aprovação. Este trabalho se desenvolve através de uma abordagem quanti-qualitativa (Vieira, 2004, p. 15).

\section{Revisão bibliográfica}

Para embasar as discussões do tema, analisamos primeiramente as reflexões normativas e teóricas referentes à preservação da memória institucional digital do registro de projetos da UFSM, no âmbito do Centro de Artes e Letras CAL.

Tem-se inicialmente a premência de postura proativa do profissional arquivista necessária à 
mudança de paradigma, do custodial para o pós-custodial.

Cita-se Ribeiro (2005, p. 7) para enfatizar a mudança de paradigma:

A simbiose entre a informação e a tecnologia digital veio pôr em causa a noção estática e duradoira de "documento" (tendencialmente identificado com mensagens registradas num suporte papel) como conceito operatório e como objecto de estudo e marcou a entrada dos arquivos e da Arquivística na chamada "era pós-custodial".

Recorre-se também a Silva (2010, p. 10) para reforçar a mudança de paradigma:

[...] baseada em dois paradigmas essenciais: o custodial, patrimonialista, historicista e tecnicista, que surge a partir do séc. XVIII até a era da Informação em que vivemos; e o pós-custodial, informacional e científico, que tenderá a formatar o modo de ver, de pensar e de agir de gerações de cientistas e profissionais da informação, ao longo do séc. XXI [...].

Ainda quanto a premência da postura proativa, cita-se a contribuição de Cook (2012, p. 125) que também trata da quebra de paradigma na Arquivologia enfatizando, a pós-modernidade que agrega o questionamento da objetividade do documento na modernidade, a "naturalidade". Onde se cita:

Para os arquivistas, a mudança de paradigma requer deixar de identificar a si mesmos como guardiões passivos de um legado herdado, para celebrar o seu papel na formação ativa da memória coletiva (ou social).

Outro pesquisador que se alinha a Cook (2012) em relação a pós-modernidade na arquivilogia é Ketelaar (2001), que postula o questinamento, o que denomina de narrativas tácitas, como meio para "compreender os siginificados dos arquivos". Entende-se que esta narrativa tácita, carece de transparência e formalidade na construção do fazer arquivístico (Ketelaar 2001, p. 131):

I advocate that archival fonds, archival documents, archival institutions, and archival systems contain tacit narratives which must be deconstructed in order to understand the meanings of archives.

A pesquisadora Gilliland (2010) coaduna-se a Cook (2012( e a Ketellar (2001) no sentido de chamar os profissionais arquivistas a terem ações proativas em espaços e oportunidades onde os mesmos atuam profissionalmente (Gilliland, 2010, p. 336):

E onde existem lacunas documentais, a partir da perspectiva de estratégias de documentação, os arquivistas devem intervir ativamente com projetos de documentários, como histórias orais ou colec- cionismo temático para a criação de um "record" que preenche a experiência ou conhecimento que falta, em vez de agir como receptores passivos de burocrático subprodutos.

Pertinente aos cuidados de preservação recorre-se a Ferreira (2006, p. 52), quando esse trata da complexidade de manter um sistema com todos os requisitos de preservação:

Quanto maior for o número de propriedades significativas, maiores serão os requisitos relativos à infraestrutura tecnológica necessária para suportar a preservação.

A preservação digital não prescinde de se tratar de metadados que é um elemento que reforça o valor do documento de arquivo e para isso recorre-se à Norma ISO n. 15.489-1, que enfoca a gestão de documentos.

Os metadados fornecem informações arquivísticas principalmente sobre a produção do documento. Constituem-se no detalhamento de todas as modificações/alterações procedidas no documento, ou seja, apresentam informações arquivísticas contextuais sobre as atividades da organização na etapa de produção do documento.

Para o enfoque da memória que se aborda neste trabalho, cita-se Huyssen $(2000$, p. 9) onde destaca a evidência social da memória nos últimos anos em que declara de forma contundente que é:

Um dos fenômenos culturais mais surpreendentes dos anos recentes é a emergência da memória como uma das preocupações culturais e políticas centrais das sociedades ocidentais.

O banco de dados tem seu reconhecimento associado à questão de pertencimento que a sociedade dispensa a ele como instrumento de "empoderamento" da informação, que conforme Coelho (2003, p. 3) diz:

Um banco de dados não é tudo e pode ser nada. Mas, se for alguma coisa será um instrumento de empoderamento da sociedade cível.

\section{Considerações teórico-críticas sobre o módulo de registro de projetos como parte da memória institucional sob a ótica da NBR 15.472 - SAAI}

As considerações são elencadas tendo como referência a Norma Brasileira - NBR 15.472 SAAI, aplicada ao sistema registro de projetos da UFSM. São abordados os tópicos da seção 4. Discorre-se sobre os conceitos básicos do SAAI, a qual, inicialmente, define a expressão "arquivo" em sentido amplo, ou seja, abrangendo todo o espectro que constitui o acervo infor- 
macional, isto é, o conjunto de funções e estruturas organizacionais de uma entidade.

A explosão da capacidade de processamento computacional e das mídias digitais tem levado a situações nas quais a função do produtor e a função do arquivo residem em uma mesma entidade (ABNT, 2007).
Contextualizando a definição de arquivo da norma ao SIE no módulo de projetos de ensino, extensão e pesquisa, desde 1992, observa-se que o mesmo se constitui como fonte de informações/dados. Associa-se a referida norma recomendada para compor um repositório da produção institucional tendo como fonte o SIE. Conforme a figura 1 de entrada de registro de projetos composta por metadados.

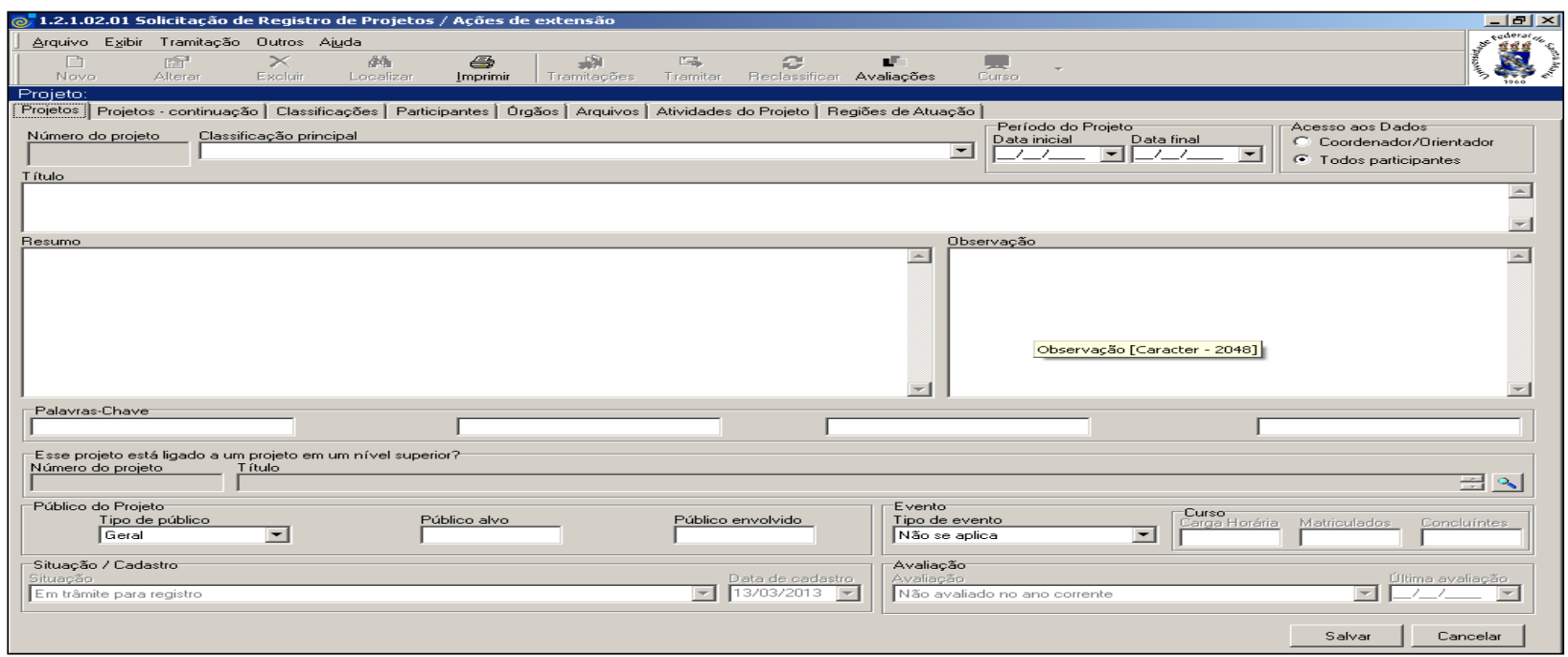

Figura 1. Interface do registro de projeto: primeira tela (Fonte: SIE/UFSM)

Cabe enfatizar que o registro de projetos no banco de dados da instituição, ou seja, o registro do que já se fez e se faz, em termos de projetos de ensino, pesquisa e extensão na instituição constituem-se como patrimônio documental conforme a Constituição de $1988 \mathrm{em}$ seu artigo 216 que diz: "Constituem patrimônio cultural brasileiro [...] III - as criações científicas, artísticas e tecnológicas; IV - as obras, objetos, documentos [...]" (Brasil, 1988).

Tratando-se de uma instituição de ensino superior, que tem como um de seus objetivos o desenvolvimento da pesquisa, e essa deve ser incorpora à memória da ciência e da tecnologia nacional preconizada pelo Conselho Nacional de Desenvolvimento Científico e Tecnológico, $\mathrm{CNPq}$, instituição reguladora e fomentadora da pesquisa científica e tecnológica brasileira, através de uma Política Nacional de Preservação da Memória da Ciência e da Tecnologia através de uma Comissão Especial CNPq (2003, p. 3). A Comissão Especial do CNPq (2003), diz:

Universidades, institutos de ciência e sociedades científicas, em franco menosprezo as suas funções sociais e a sua importância histórica, não preservam documentos inestimáveis para o reconhecimento do trabalho de seus professores, pesquisadores [...].

\subsection{O ambiente SAAI na perspectiva do SIE}

A norma propicia uma visão macro do ambiente que gravita o SAAI conforme figura 2 .

Constata-se que o SAAI interage com o entorno de uma forma hermética, ou seja, ele não mantém interação fora dos padrões estabelecidos formalmente com os entes que compõem o ambiente macro. Pode-se dizer que o SAAI se constitui de uma estrutura macro de metadados de preservação e acesso agendados previamente.

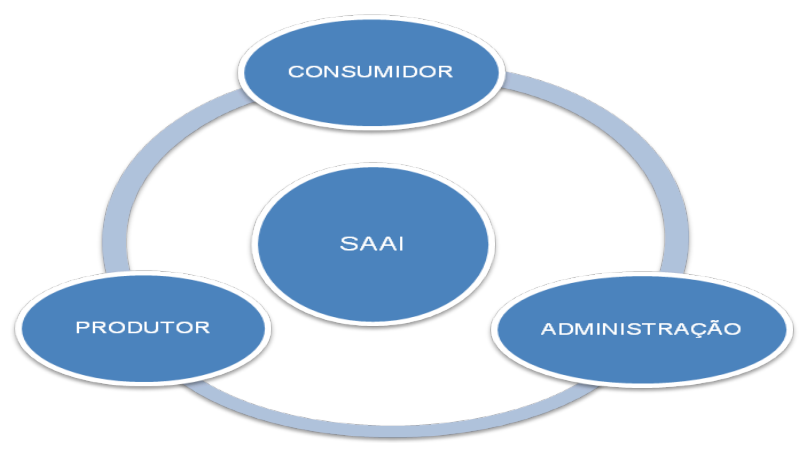

Figura 2. Constituição do ambiente do SAAI

O produtor no caso do SIE, módulo de projetos, é o papel desempenhado pelo coordenador de 
projeto, onde lança todos os dados nos respectivos campos estruturados como metadados, conforme a figura 1. Cabe citar que nesse módulo de registro de projetos, o coordenador de projeto assume a função de produtor no SAAI.

$O$ agente que desempenha o papel de consumidor no SIE, no módulo de registro de projetos pode variar, ou seja, o próprio produtor, ou administrador pode vir a ser o consumidor. Simulando essa situação no ambiente SIE do módulo projetos tem-se a figura do consumidor, podendo ser: a(s) pró-reitoria(s), os departamentos onde os coordenadores de projetos trabalham. Conforme discorrido acima, os interesses de produtores e consumidores, assim como dos administradores são dispares. Esta disparidade fica evidenciada no trato de documentos do meio científico, observa-se conforme Silva (2007, p. 22) que existe um distanciamento entre $o$ arquivista e o pesquisador ocasionando um vácuo na questão da produção, da preservação e do acesso aos documentos:

Não há clareza sobre quais documentos oriundos da prática científica devem ser preservados. Tão pouco há clareza, por parte de cientistas, de administradores e de historiadores, do que seja documento de arquivo. Muitas vezes, nem os próprios arquivistas [...].

\subsection{Informação no SAAI}

Um tópico da SAAI, NBR 15.472 na seção 4, trata de Informação como sendo: "[...] qualquer tipo de conhecimento intercambiável, sendo sempre expressa por algum tipo de dado" (ABNT 2007, p. 10). Essa definição pressupõe uma dinâmica para se chegar à informação, ou seja, é um processo do qual se tem conforme a figura 3.

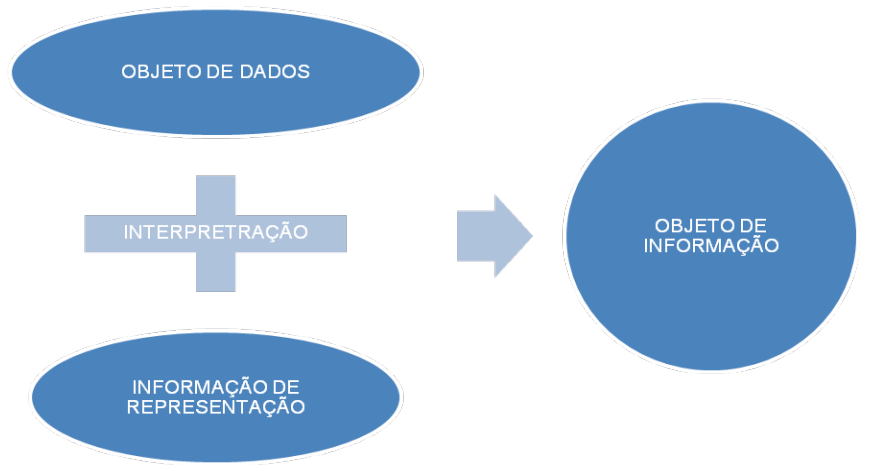

Figura 3. Constituição do objeto de informação

Nessa dinâmica para se chegar ao objeto de informação desejado é imprescindível que o SAAI processe o entendimento dos dados e da informação de representação, compatível com a base de conhecimento da comunidade-alvo. Cabe destacar o que Lara $(2001$, p. 7) diz a respeito do interesse do usuário que busca a informação:

[...] para haver informação é preciso que ela faça sentido para alguém, ou seja, que exista algum nível de compartilhamento a partir do qual se estabeleça um vínculo para a interpretação e o sentido.

Associa-se a dinâmica de formação do objeto de informação ao SIE, módulo de registro de projetos. O SIE propicia o recurso aos usuários comuns (produtores/coordenadores de projetos) da geração de relatórios operacionais de sua base de dados relativas a projetos pelos quais os respectivos produtores respondem, conforme a figura 1.

\subsection{Pacote de informação}

Passa-se a discorrer sobre pacote de informação que é (ABNT 2007, p. 11):

[...] um recipiente conceitual de dois tipos de informação chamados de informação de conteúdo e informação de descrição e preservação.

Outra informação pertinente ao assunto é a informação de empacotamento, que, por sua vez, poderá ser localizado pela informação descritiva do respectivo pacote, na $6^{\mathrm{a}}$ posição conforme, demonstra-se na ordenação de $1^{\mathrm{a}}$ a $6^{\mathrm{a}}$ na figura 4.

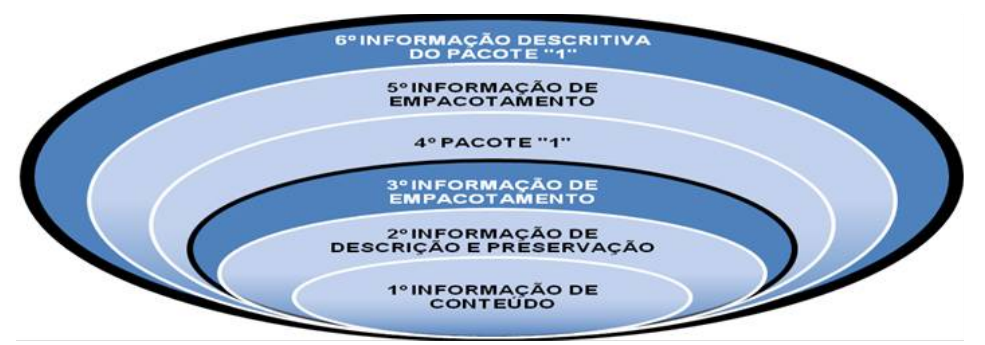

Figura 4. Posição da informação de descrição do empacotamento

Cabe ressaltar que a informação de conteúdo é (ABNT 2007, p. 12).

[...] aquela informação-alvo original da preservação. Consiste no objeto de dados de conteúdo (objeto físico ou objeto digital, isto é, os bits) e a sua informação de representação associada, necessária para tornar o objeto de dados compreensíveis para comunidade/alvo.

Enfatiza-se que a objetivação da informação de conteúdo não prescinde a informação de descrição e preservação, visto que ela propicia a sua identificação e contextualização de onde foi produzida. A informação de descrição e preser- 
vação constitui-se de 4 (quatro) tipos, conforme demonstrado a seguir.

\begin{tabular}{ll}
\hline Tipos & Objetivo \\
\hline Proveniência & Manter o histórico físico e digital \\
\hline Contexto & $\begin{array}{l}\text { Explicitar o ambiente onde foi } \\
\text { produzida e suas relações. }\end{array}$ \\
\hline Referência & $\begin{array}{l}\text { Estabelecer um identificador único e } \\
\text { cruzamentos possíveis }\end{array}$ \\
\hline Fixidez & $\begin{array}{l}\text { Assegurar a blindagem quanto a } \\
\text { alterações não autorizadas. }\end{array}$ \\
\hline
\end{tabular}

Quadro 1. Tipos de informações de descrição e preservação

Conforme a figura 5, a informação de empacotamento expressa a organização lógica propiciada pela união da informação de conteúdo e a informação de descrição e preservação.

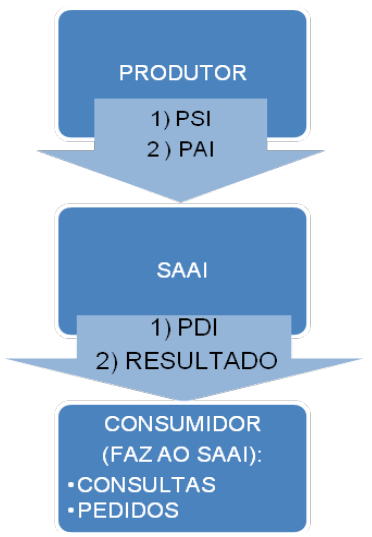

Figura 5. As relações externas do SAAI

A informação descritiva, conforme a figura 5 constitui-se da informação necessária para localizar o pacote com a informação de conteúdo desejada. Essa informação poderá ser disposta na forma de catálogo ou outra ferramenta de busca. Associa-se os quatro tipos de informação de descrição e preservação ao SIE que embora não sendo um repositório deveria ser dotado dessas informações como requisitos imprescindíveis à consistência dos dados que gera e preserva.

\subsubsection{Variações do pacote de informação}

Quanto aos pacotes de informação, tem-se uma variação e distinções entre os pacotes de informações preservados pelo SAAl, considerando a completude ou não da informação de representação e da informação de descrição de preservação - IDP da informação de conteúdo: a primeira variação é a do pacote de submissão de informação - PSI que é o pacote encaminhado do órgão produtor ao SAAI. Normalmente, dentro do processo de tramitação das informações, são necessários vários desses pacotes (PSI) à composição de um pacote de arquivamento de informação PAl, conforme figura 5. Considerando-se a completude ou não, dos pacotes de informações dispostas para, submissão convencionada entre as partes, reputa-se pertinente a citação de Benjamin (1986, p. 206) quando diz que: "Com efeito, o homem conseguiu abreviar até a narrativa" (short story).

Vale salientar que essa preocupação de Benjamin (1986), também faz parte do universo arquivístico e que se aplica à realidade do banco de dados da UFSM, ou seja, existe uma preocupação por parte dos profissionais arquivistas e dos usuários do sistema em manter a totalidade das informações armazenadas no banco de dados da instituição. Obviamente, respeitando os parâmetros normativos tal como os temporais.

\subsubsection{Interações externas de alto nível do SAAI}

Um SAAI pode estabelecer relações com instituições externas na forma de prestação de serviços remunerados, ou seja, a comercialização de informações. As interações externas de alto nível do SAAI abrangem o produtor, o SAAI e o consumidor, conforme a figura 5 .

Passa-se a descrever sucintamente as interações externas do SAAI. Inicialmente tem-se a submissão sob a forma de pacote de submissão de informação - PSI para o SAAI por parte do produtor, constituindo o pacote de arquivamento de informação - PAl ou os pacotes que passam a ser preservados no SAAI. Ainda, no decorrer desse fluxo, o consumidor aciona o SAAI através de consultas e/ou pedidos imediatos ou programados de informações armazenadas no SAAI. Consecutivamente, o SAAI disponibiliza ao consumidor o resultado na forma de pacote de disseminação de informação - PDI, conforme os padrões estabelecidos no sistema e acordados com o consumidor.

Analogamente $o$ processo de interação do SAAI, ao SIE, no módulo de registro de projetos, constata-se idiossincrasias de grupos ou áreas do conhecimento que fazem parte da UFSM, ou seja, a diversidade de áreas Sociais e Humanas, Naturais e Exatas configurando interesses e complexidades distintas em obter informações oriundas do SIE, principalmente voltados para a pesquisa.

O SIE sendo a ferramenta institucional de uso contínuo e legitimado por todos os segmentos da instituição faz com que o mesmo se constitua como memória coletiva, uma vez que os atores 
que fazem parte deste cenário, associando-se a Pollak (1989, p.3), quando fala sobre a memória coletiva no que se refere ao sentimento de pertencimento:

[...] uma memória estruturada com suas hierarquias e classificações, uma memória também que, ao definir o que é comum a um grupo e o que o diferencia dos outros, fundamenta e reforça os sentimentos de pertencimento e as fronteiras socioculturais.

\section{Considerações finais}

A partir da análise sobre a preservação da memória institucional relativa a projetos no sistema de informação para o ensino - SIE, sob a ótica do modelo de referência para um sistema aberto de arquivamento de informação - SAAI, NBR 15.472, da seção 4 (quatro), temos as seguintes considerações:

Observa-se a partir da tela inicial de registro de projeto, que a mesma, assim como as demais são estruturadas com uma interface estruturada através de metadados, conforme figura 1, coadunando-se com os princípios do SAAI.

Verifica-se que o conceito e a constituição de informação/objeto de informação no ambiente SAAI, é semelhante ao SIE, à medida que os relatórios gerados a partir do mesmo são compostos por combinações de metadados associados à base de conhecimento dos usuários/consumidores.

Averigua-se que a informação de descrição dos pacotes de informação, não prescinde de requisitos de proveniência, de contexto, de referência e fixidez, resguardando a autenticidade e confiabilidade da complexa variação de pacotes: PSI, de PAI e de PDI no SAAI.

Portanto, pretende-se a partir deste trabalho, desenvolvido sob o enfoque teórico e institucional, que ele sirva aos administradores da instituição, como subsídio para as possíveis modificações que julgarem necessárias no sistema. Visto que as informações que fazem parte do sistema de registro de projeto constituem-se como fonte de informação, podendo ser utilizadas para pesquisa das mais variadas áreas e interesses. Para isso, as informações precisam ser acessíveis, consistentes e confiáveis.

\section{Referências}

Associação Brasileira de Normas Técnicas (ABNT). (2007) NBR 15472: Sistemas espaciais de dados e informações - Modelo de referência para um sistema aberto de arquivamento de informação (SAAI). http://www.target. com.br/previewer-v1/Viewer.asp?nbr=40341\&token=d7f 29e8c-88cd-4938-a5e2-01a2fc44e260\&sid=5mgwtipqku udwxbjysxiv1b3\&email $=(2014-07-12)$

Benjamin, Walter. (1996) O Narrador. Obras escolhidas: magia e técnica, arte e política. 10. São Paulo: Brasiliense.

Brasil. Constituição da República Federativa do Brasil de (1988).http://www.planalto.gov.br/ccivil_03/Constituicao/ Constitui\%C3\%A7ao.htm (2014-07-12)

CNPq. Conselho Nacional de Desenvolvimento Científico e Tecnológico. (2003) Comissão Especial. Proposta de Política Nacional de Memória da Ciência e da Tecnologia: relatório da Comissão Especial. Ministério da Ciência e Tecnologia,. http://centrodememoria.cnpq.br/poli ticadememoria.pdf (2013-6-20).

Coelho, Teixeira. (2003) Banco de dados: do inerte cultural à cultura da vida. // Políticas culturais para o desenvolvimento: uma base de dados para a cultura. Brasília: UNESCO Brasil. 217-232.

CONARq, Conselho Nacional de Arquivos; Câmara Técnica de Documentos Eletrônicos. http://www.documentos eletronicos.arquivonacional.gov.br/media/publicacoes /glossario/2010glossario_v5.1.pdf. (2013-06-14).

Cook, Terry. (2012) Arquivologia e Pós-modernismo: novas formulações para velhos conceitos. // Informação Arquivística. 1:1 123-148. http://www.aaerj.org.br/ojs/index .php/informacaoarquivistica/article/view/9 (2014-07-12).

Ferreira, Miguel (2006) Introdução à preservação digital conceitos, estratégias e actuais consensos. Guimarães, Portugal: Escola de Engenharia da Universidade de Minho.

Gilliland, Anne. (2010) Epílogo: dentro e fora dos arquivos. // Arquivo Ciência. 1:3, 333-343. http://link.springer.com/ar ticle/10.1007/s10502-010-9134-x/fulltext.html

Huyssen, Andréas (2000). Seduzidos pela memória. Rio de Janeiro: Aeroplano.

Ketelaar, Eric. (2001) Tacit narratives: the meanings of archives. // Archival Science. 1:2, 131-141. http://fkete laa.home.xs4all.nl/TacitNarratives.pdf (2014-07-12).

Lara, Maria Lopes Ginez de (2001). O unicórnio (o rinoceronte, o ornitorrinco...), a análise documentária e a linguagem documentária. // DataGramaZero. 2:6 (12). http://www.dgz.org.br/dez01/Art_03.htm (2014-07-12).

Pollak, Michael (1989). Memória, esquecimento, silêncio. /I Estudos Históricos. 2:3, 3-15. http://www.uel.br/cch/cdph/ arqtxt/Memoria_esquecimento_silencio.pdf (2014-07-12).

Ribeiro, Fernanda. (2005) Os arquivos na era pós-custodial: reflexões sobre a mudança que urge operar. 129-133. http://repositorio-aberto.up.pt/handle/10216/14000 (2013-07-05)

Silva, Maria Celina Soares de Mello (2007). Visitando laboratórios: o cientista e a preservação de documentos. Tese (História Social) - Faculdade de Filosofia, Letras e Ciências Humanas da Universidade de São Paulo, São Paulo. http://www.teses.usp.br/teses/disponiveis/8/8138/ tde-18102007-141253/pt-br.php (2014-07-12).

Silva, Armando Malheiros da (2010). Mediações e mediadores em Ciência da Informação. // Prisma.com. Porto. 9 1-37. http://revistas.ua.pt/index.php/prismacom/article/vi ew/700 (2014-07-12)

Vieira, Marcelo Milano Falcão. (2004) Por uma boa pesquisa qualitativa. Vieira, Marcelo Milano Falcão Zouain, Debora Moraes.(eds.). Pesquisa qualitativa em administração. 2. Rio de Janeiro: FGV, 2004. 13-28.

Enviado: 2014-04-01. Segunda versión: 2014-06-02. Aceptado: 2014-08-14. 